\footnotetext{
Jelena Opačić, dipl. inž.

Vojnotehnicki institut,

Beograd
}

\section{BEŽIČNA MREŽNA TEHNOLOGIJA BLUETOOTH}

UDC: $621.39: 654.16: 681.324$

Rezime:

$U$ narednim godinama raznovrsni uredaji, od Eelijskih telefona $i$ laptopova do personalnih digitalnih pomocnih sredstava $i$ kucnih aparata, biće u mogućnosti da komuniciraju i budu medusobno povezani korišćenjem nove visoko-brzinske, mikrotalasne, bežične, link tehnologije male snage nazvane Bluetooth. Sadržaj ovog rada čine pregled tehnologije, standardizacija i primena Bluetootha.

Ključne reči: Bluetooth, tehnologija, bežični prenos, mreža, PAN.

\title{
WIRELESS NETWORKING TECHNOLOGY BLUETOOTH
}

\section{Summary:}

In the years to come, variety of devices, from cell phones and laptops to personal digital assistants and household appliances, will be capable of communicating and interoperating with one another using a new high-speed, low-power microwave wireless link technology called Bluetooth. The overview of this technology, standardization and application of Bluetooth are the contents of this paper.

Key words: Bluetooth, technology, wireless transmission, network, PAN.

\section{Uvod}

Bežični servisi su reprezent napretka tehnologije $i$, verovatno, otvaraju novu eru u razvoju telekomunikacija. Međutim, ovi servisi su u upotrebi duže od jednog veka, i za njih se još upotrebljava sinonim „radio“. Pri korišcenju telekomunikacionih usluga susreće se sa ograničenjima koja potiču od žičanih mreža, tako da je od poslednje dekade prošlog veka došlo do porasta primene bežičnih komunikacija, što je privuklo pažnju poslovnih udruženja, proizvođača i stručnih krugova. Upotreba bežične mreže tehnologije potvrdila je da ona može da podrži dobre osobine koje pružaju žicane mreže, uz pružanje dodatne povoljnosti slobode računarskog rada.

$U$ ovom radu dat je pregled bežične mrežne tehnologije Bluetooth i njena standardizacija.

\section{Bežične mreže}

Osamdesetih godina prošlog veka FCC (Federal Communications Commission), propisala je standard za bežične 
mreže 802.11 IEEE. Njegov cilj je bio da se standardizuje razvoj bežičnih mreža u ISM (Industrial, Scientific and Medicine) frekvencijskim opsezima. Ovi opsezi obuhvataju frekvencije od 902 do 928 $\mathrm{MHz}, 2400$ do $2483,5 \mathrm{MHz}$ i 5725 do $5850 \mathrm{MHz}$. Danas je najpopularniji standard $802.11 \mathrm{~b}$ kojim se reguliše prenos do $11 \mathrm{Mbit} / \mathrm{s}$ podataka, pri cemu domet signala zavisi od prepreka, materijala i linije posmatranja.

Komponente bežične mreže ukljucuju bežičnu adaptersku karticu i primopredajnik, drugačije nazvan access point (AP). Mrežna adapterska kartica je umetnuta u kompjuterski PCMCIA slot. Centralno lociran AP emituje i prima signale ka i od kompjutera u okruženju, koristeći adapterske kartice. Adapter propusta signale između bežičnih kompjutera i žičane mreže koristeći razlixite signalne tehnike.

Signalne tehnike koje su standardne za bežične mreže su: infracrvena, laserska, uskopojasna mikrotalasna i prosirenog spektra (spread spectrum).

Infracrvena (IrDA) tehnologija je vrlo brza bežična tehnologija, ali je i najmanje pouzdana jer njene signale može zaustaviti najmanja prepreka. Ova tehnologija koristi infracrveni snop svetlosti za prenos signala ili informacija izmedu kompjutera, stampača, PDA (personal digital assistants) uredaja i drugih uređaja. Infracrvena tehnologija predaje signale velikim brzinama zahvaljujuci svom velikom propusnom opsegu. Postoje cetiri tipa infracrvene tehnologije i to su: lineof-sight, scatter, reflective i sirokopojasni opticki telepoint.

Laserska signalna tehnika je slična infracrvenoj signalnoj tehnici pri cemu je za nju potrebno obezbediti direktnu liniju posmatranja izmedu uredaja u vezi, i svaki objekat koji se nade na putu linije posmatranja prekida laserski prenos i blokira transmisiju. Laserska tehnologija je znatno osetljivija na spoljne smetnje od infracrvene tehnologije.

Uskopojasna mikrotalasna tehnologija je sliæna radiodifuziji radio-stanice. Radiodifuzni domet je $5000 \mathrm{~m}^{2}$, a signal ne može proći kroz celik ili noseće zidove. Ova tehnologija koristi segmente radio spektra od 18,82 do $19,205 \mathrm{GHz}$ i licencirana je od FCC.

Tehnika prenosa u prosirenom spektru (PPS) postaje jedna od najefikasnijih i najpouzdanijih tehnika radio-prenosa. Od više tehnika prenosa u proširenom spektru najzastupljenije su tehnike direktne sekvence (DS) i frekvencijskog skakanja (FH).

Kod direktne sekvence nosilac se moduliše pseudoslučajnom ( $\mathrm{PN}$ ) sekvencom cija je brzina prenosa mnogo veća od brzine prenosa modulišuceg signala koji se prethodno digitalizuje i sabira sa PN sekvencom po modulu 2. Na ovaj nacin dobija se siri radio-spektar od radio-spektra potrebnog za prenos modulišceg signala bez PPS. Ovaj odnos sirina radio-spektra PN sekvence i sirine radiospektra modulisućeg signala naziva se procesno pojačanje.

Kod frekvencijskog skakanja nosilac se pomera za diskretan prirastaj frekvencije diktiran kodnom sekvencom. Kod uređaja posebne namene obično kodna sekvenca predstavlja poverljiv podatak, i mora da bude poznata na prijemnom mestu. Vreme zadržavanja na jednoj uCestanosti može biti konstantno, ali može biti i promenljivo do pseudoslucajnog. 
Bluetooth je danas dobro ustanovljen komunikacioni standard za bežǐne veze na kratkim rastojanjima. Bluetooth zamenjuje mnoge odgovarajuce kablove koji povezuju jedan uređaj sa drugim, pomoću univerzalnog radio-linka kratkog dometa. Bluetooth radio-tehnologija, takode, obezbeduje univerzalni most ka postojećim mrežama podataka, periferijski interfejs i mehanizam za formiranje malih, privatnih ad hoc povezanih grupa uređaja, udaljenih od fiksnih mrežnih infrastruktura.

Perspektiva razvoja bežiěne tehnologije ogleda se kroz razlicite realne korisničke scenarije na svetskom nivou, što uslovljava primenu razlicitih tehnologija. Osnovni korisnički scenariji bežične konektivnosti su:

- Wireless Personal Area Networking (WPAN),

- Wireless Local Area Networking (WLAN),

- Wireless Wide Area Networking (WWAN).

WPAN predstavlja aplikaciju bežixne tehnologije koja se odnosi na personalne korisnicke scenarije. Naglasak je na trenutnoj konektivnosti izmedu uredaja, pri ‘emu se upravlja personalnim podacima ili se olakšava razmena podataka izmedu male grupe pojedinaca. Bluetooth je viden kao nosilac prenosa podataka za PAN mreže.

WLAN mreža je bazirana na organizaciji konektivnosti drugacijoj nego što je to kod žicano baziranih LAN veza. Cilj WLAN tehnologije je da clanovima radnih grupa obezbedi pristup poslovnim mrežnim resursima sa mogućnošću vršenja razmene ili raspodele podataka, apli- kacija ili pošte, ali na takav način da to ne utice na mobilnost korisnika.

Dok se WLAN odnosi na konektivnost unutar definisanog regiona, WWAN se odnosi na potrebu da se ostane u vezi krećući se i izvan tih granica regiona. Danas celijska tehnologija omogucava bežičnu konektivnost kompjutera bilo preko kablova do celijskog telefona ili preko PC Card celijskog modema.

\section{Pregled Bluetooth tehnologije}

\section{Princip rada}

Bluetooth je mikrotalasna bežična link tehnologija male snage $i$ velikog informacionog protoka, projektovana da poveže telefone, laptopove, PDA uređaje i drugu portabl opremu zajedno, sa malim ư̌esćem ili bez učesća korisnika. $\mathrm{Za}$ razliku od infracrvene tehnologije, Bluetooth ne zahteva opticku vidljivost za rad uresnika u vezi. Kod ove tehnologije primenjene su modificirane postojeće bežicne LAN tehnike, ali je najzapaženija po malim gabaritima i niskoj ceni. Kola tekućeg prototipa smeštena su na plocicu povrsine $0,9 \mathrm{~cm}^{2}$, pri cemu je u toku razvoj mnogo manje verzije realizovane u jednom cipu. Ocekuje se da će cena uređaja vrlo brzo pasti sa pocetne od 20 USD na 5 USD u narednih par godina. Takode, oxekuje se da ce se Bluetooth više koristiti u sastavu opreme nego kao pojedinazni uredaj.

Ovu tehnologiju karakteriš vrlo fleksibilna mrežna topografija. Kada se Bluetooth proizvod nade u oblasti pokrivanja drugog proizvoda (rastojanja od 10 $\mathrm{cm}$ do $100 \mathrm{~m}$ ) oni automatski razmenjuju adrese i karakteristicne detalje. Zatim us- 
postavljaju pouzdan $1 \mathrm{Mb} / \mathrm{s}$ link (do 2Mbps u drugoj generaciji tehnologije) sa korekcijom greške, koji se koristi prema zahtevima. Protokoli podržavaju govor i podatke. Radio funkcionise na opstedostupnom nelicenciranom radio-opsegu od $2,402 \mathrm{GHz}$ do $2,480 \mathrm{GHz}$ (sa mogućnošcu da međunarodni putnici koriste Bluetooth opremu), i obezbeduje brzinu podataka do $721 \mathrm{Kbps}$, kao i tri kanala za prenos govora. Ova tehnologija realizuje se umetanjem malih, jeftinih primopredajnika kratkog dometa u električne uređaje koji su danas dostupni. Bluetooth moduli mogu se ugradivati u električnu opremu ili koristiti kao adapteri. Na primer, u PC-ju se može ugraditi u PC card ili spolja postaviti preko USB porta. Na slici 1 prikazani su razliciti funkcionalni blokovi Bluetooth sistema.

Svaki uređaj ima jedinstvenu 48-bit adresu prema IEEE 802 standardu. Veze mogu biti point-to-point ili multipoint. Maksimalni domet iznosi $10 \mathrm{~m}$, ali može biti prosiren na $100 \mathrm{~m}$ uz povećanje snage. Bluetooth uređaji su zaštićeni od radio-interferencije zahvaljujući proizvoljnoj promeni frekvencije od maksimalno 1600 skokova u sekundi, zbog primenjene tehnike frekvencijskog skakanja. Oni, takode, koriste tri razlicite seme za korekciju greske. Obezbeđena je i ugrađena enkripcija i verifikacija. Bluetooth uređaji nemaju preciziranu potrošnju baterije tako da je potrosnja snage uređaja u „hold“" režimu $30 \mu \mathrm{A}$, da bi u aktivnom režimu iznosila 8 do $30 \mathrm{~mA}$ (ili manje od $1 / 10 \mathrm{~W}$ ). Radio- $\mathrm{Cip}$ trosi samo $0,3 \mathrm{~mA}$ u standby režimu, što je za $3 \%$ manje od snage koju koristi standardni mobilni telefon. Čipovi, takođe, imaju odlicne karakteristike cuvanja energije, tako da se uređaj automatski prebacuje u režim male potrosnje snage kada se obim saobracaja smanji ili prestane. Bluetooth uredaji su klasifikovani u tri razlicite klase prema izlaznoj snazi. Klasu 1 karakterise maksimalna predajna snaga od $+20 \mathrm{dBm}$ (100 mW), klasu 2 karakteriše maksimalna predajna snaga od $+4 \mathrm{dBm}(2,5 \mathrm{~mW})$, a klasu 3 karakterise maksimalna predajna snaga od $0 \mathrm{dBm}(1 \mathrm{~mW})$.

Pored toga sto se upotrebom ovakvih uredaja zamenjuju kablovi, Bluetooth tehnologija obezbeđuje univerzalni most ka postojećim mrežama, periferijski interfejs i mehanizam za stvaranje malih, privatnih ad hoc povezanih grupa uredaja udaljenih od fiksnih žicanih infrastruktura. Projektovana je da radi u sumnim radio-frekvencijskim sredinama, tako da Bluetooth radio koristi brzu potvrdu $\mathrm{i}$ frekvencijsko skakanje sto link cini robusnim. Bluetooth radio-moduli izbegavaju interferenciju od drugih signala skačcuci na novu frekvenciju posle predaje ili prijema paketa. U poređenju sa drugim sistemima koji rade $u$ istom frekvencijskom opsegu, Bluetooth radio tipienno skače brže i koristi kraće pakete. Ovo ga

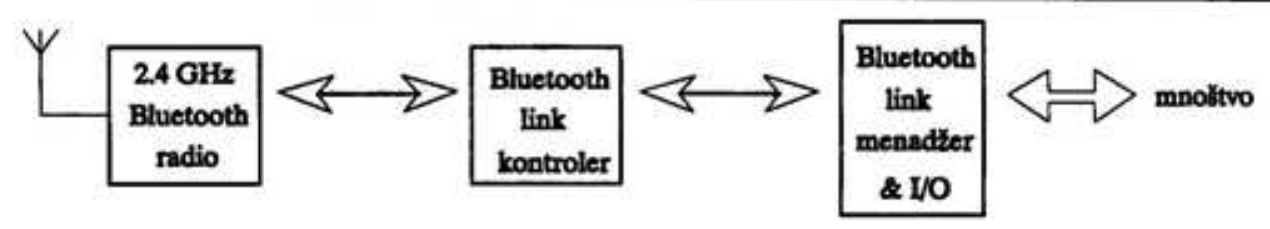

SI. I- Različiti funkcionalni blokovi Bluetooth sistema 
Cini robusnijim nego sto su to drugi sistemi. Korišcenjem FEC (Forward Error Correction) ograničava se uticaj slucajnog suma na linkovima kod velikih udaljenja. Kodiranje je optimizovano za nekoordinisan prostor.

Bluetooth garantuje sigurnost na bitskom nivou. Autentičnost kontroliše korisnik korišcenjem 128 bit-skog kljuca. Radio-signali mogu biti kodirani sa 8 bit-a ili sve drugo do 128 bit-a. Bluetooth radio-transmisija biće prilagođena sigurnosnim standardima koje zahtevaju države u kojima ce se ta tehnologija koristiti, uvažavajući efekte koje radio-transmisija ima na ljudski organizam. Emisije od Bluetooth uređaja nece biti veće od emisija industrijski standardizovanih i bežicnih telefona. Bluetooth modul ne unosi interferenciju niti prouzrokuje stetu javnim ili privatnim telekomunikacionim mrežama.

Bluetooth protokol u osnovnom opsegu predstavlja kombinaciju komutacije kanala (CS) i paketske komutacije (PS). Paket nominalno pokriva jedan slot, sa mogućnošću prosirenja pokrivanja do 5 slotova. Bluetooth može podržati asinhroni kanal podataka, zatim do tri simultana sinhrona kanala govora, ili kanal koji simultano podržava sinhroni podatak i sinhroni govor. Svaki kanal za prenos govora podržava $64 \mathrm{~kb} / \mathrm{s}$ sinhroni link za prenos govora. Asinhroni kanal podržava asimetrični link od maksimalno $721 \mathrm{~kb} / \mathrm{s}$ u oba pravca, obezbeđujući $57,6 \mathrm{~kb} / \mathrm{s}$ u povratnom pravcu ili $432,6 \mathrm{~kb} / \mathrm{s}$ simetrieni link.

\section{Interoperabilnost}

Interoperabilnost je mogućnost softvera i hardvera velikog broja uređaja raz- licitih proizvođaca da međusobno komuniciraju. Jedan od ciljeva Bluetooth SIG (Special Interest Group) je da se bežične veze ucine lakim i jednostavnim za upotrebu. Da bi se obezbedila najbolja moguca usluga korisnicima Bluetooth uređaja, kao sto je interoperativnost sa drugim Bluetooth uredajima, Bluetooth SIG je razvila logo program kojim se ozvaniCava saglasnost sa objavljenim Bluetooth standardom kao i interoperabilnost sa drugim Bluetooth uredajima. Bluetooth uređaji koji uspešno zadovolje postavljene kriterijume sticu pravo da nose zvaniCan Bluetooth logo. Postupak testiranja Bluetooth proizvoda kojim oni sticu ovo pravo je u opticaju od kraja 2000 . godine. Po programu testiranja svaki Bluetooth uređaj treba da izvrši proveru da li su drugi Bluetooth uredaji testirani na interoperabilnost. Logo program je veoma iscrpan u svom delokrugu. On uključuje ne samo radio i protokolsku interoperabilnost, već i korisnicke profile. Testiranje interoperabilnosti korisnickih profila mora se primenjivati na proizvodima koji su stekli logo, a logo program ce specificirati korisnicke profile koje ce proizvod podržati. Nivo testiranja interoperabilnosti i kvalifikacija jedinstveni su za industriju, i treba da osiguraju zajednicki rad aplikacijama cime se izlazi u susret oðekivanjima korisnika.

\section{Korisnički modeli}

Bluetooth korisnicki model zasniva se na zajedničkom povezivanju uređaja, a usredsreden je na tri kategorije i to: voice/data access point uredaje, periferijske veze i PAN mreže. 
Voice/data access point uredaji predstavljaju jedan od ključnih inicijalnih korisnickih modela koji se odnosi na povezivanje kompjuterskog uređaja na komunikacioni uređaj preko sigurnog bežǐnog linka, kao što je prikazano na slici 2. Na primer, mobilni kompjuter koji je opremljen sa Bluetooth tehnologijom može se povezati sa mobilnim telefonom koji koristi Bluetooth tehnologiju kako bi se povezao na Internet $i$ imao pristup po$\$$ ti (e-mail). Mobilni telefon ima funkciju personalne access point. Takođe, notes se može povezati na Internet dok se celijski telefon nosi u koferčiću ili u novčaniku.

Periferijske veze, druga kategorija korisnickih modela, odnosi se na zajednicko povezivanje drugih uredaja, kao sto je prikazano na slici 3. Standardne tastature, miševi i džojstici rade preko bežičnog linka. Bluetooth link se ugrađuje u mobilni kompjuter pa je cena periferijskog uređaja manja, jer access point uredaj nije potreban.

Personal Area Networking (PAN) korisnicki model, usmeren je na ad hoc formacije i slučaj kada su personalne mreže u prekidu. Na primer, kada se korisnik nalazi na aerodromu, njemu je

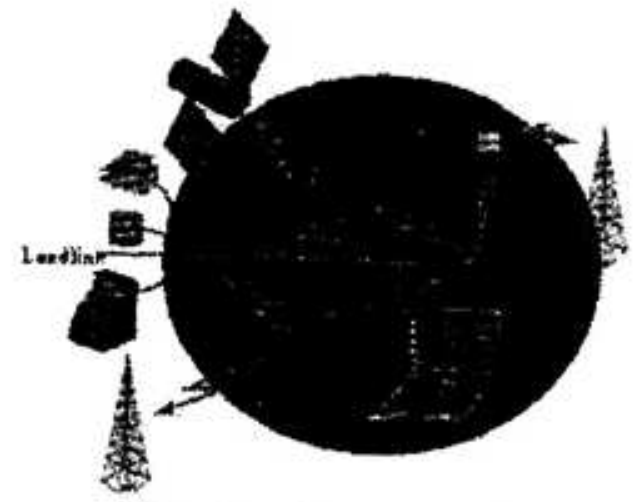

Sl. 2 - Voice/data access point

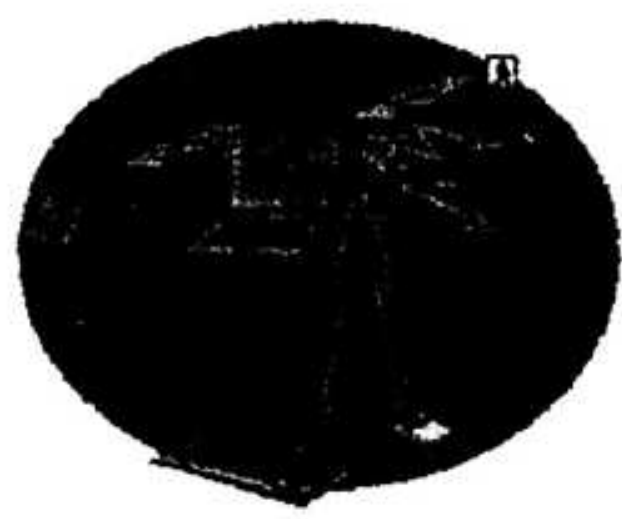

Sl. 3 -Periferijske veze

omogućena brza i sigurna razmena dokumenata uspostavljanjem privatne piconet. U budućnosti, Bluetooth „kiosci“ ce obezbedivati pristup elektronskim medijima, i moci ce brzo da se rasterete za naredni pristup mobilnog uređaja.

\section{Bluetooth radio-link}

Bluetooth radio-link se odlikuje sledecim karakteristikama:

- Frekvencijsko skakanje u prosirenom spektru:

$-2,402 \mathrm{GHz}+\mathrm{k} \mathrm{MHz}, \mathrm{k}=0, \ldots, 78$

$-1,600$ skokova u sekundi;

- GFSK modulacija:

$-1 \mathrm{Mb} / \mathrm{s}$ symbol rate;

- predajna snaga:

- $0 \mathrm{dBm}$ (do $20 \mathrm{dBm}$ sa upravljanjem snagom).

\section{Bluetooth arhitektura}

Bluetooth tehnologija je podeljena na dva standarda: core i profile specifikaciju. Core specifikacija govori o tome kako tehnologija radi, dok je profile specifikacija fokusirana na to kako izgraditi 
interoperabilne uredaje korišcenjem core tehnologije. Core tehnologija je ilustrovana na slici 4 , koja prikazuje i niže nivoe Bluetooth arhitekture.

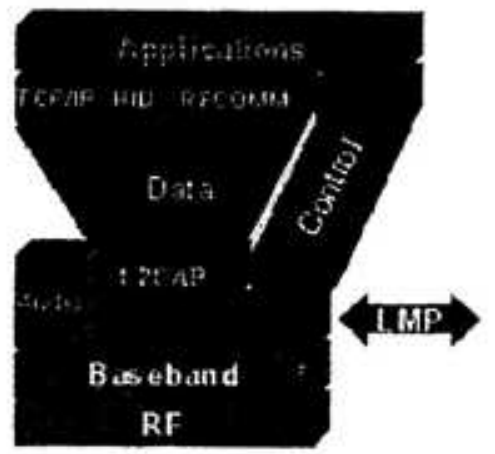

SI. 4-Bluetooth arhitektura

Radio frekvencijski nivo - Bluetooth radio-interfejs se bazira na nominalnoj predajnoj snazi od $0 \mathrm{dBm}(1 \mathrm{~mW})$ sa mogućnošću njenog rasta prema potrebama rada do $20 \mathrm{dBm}(100 \mathrm{~mW})$ sirom sveta. Radio-interfejs odgovara pravilima ISM opsega većine zemalja do $20 \mathrm{dBm}$ (Amerika, Evropa i Japan). Radio funkcioniše u prosirenom spektru tehnikom frekvencijskog skakanja u ISM opsegu sa 79 skokova šrine po $1 \mathrm{MHz}$, sa startnom frekvencijom od $2,402 \mathrm{GHz}$ do frekvencije $2,480 \mathrm{GHz}$. Nominalni domet linka je od $10 \mathrm{~cm}$ do $10 \mathrm{~m}$, ali se može proširiti na $100 \mathrm{~m}$ sa povećanjem predajne snage (koristeći opciju $20 \mathrm{dBm}$ ).

Bluetooth propusni opseg - Bazni radio je hibridni radio sa funkcionisanjem u proširenom spektru. Tipično, radio koristi frekvencijsko skakanje gde je $2,4 \mathrm{GHz}$ ISM opseg razbijen u 79 kanala od $1 \mathrm{MHz}$ kroz koje radio nasumice skace dok predajnik prima podatke.

Piconet se formira kada jedan Bluetooth radio stupi u vezu sa drugim Blue- tooth radiom. Tada oba radija zajedno skacu kroz 79 kanala. Bluetooth radio-sistem podržava veliki broj piconet, omogućavajući svakoj piconet sopstveni set slučajno skakajućih grupa frekvencija. Povremeno piconets ce se zaustaviti na istom kanalu. Kada se ovo dogodi radiji ce skociti u slobodan kanal i tada se vrši ponovni prenos (ukoliko ne dođe do gubitka podataka).

Mrežna topologija - Na slici 5 ilustrovana je tipiěna piconet sa kružićima (M, S, P ili Sb) koji predstavljaju Bluetooth radije. Oni se povezuju jedan sa drugim u piconets koje su formirane tako da se master radio simultano povezuje sa najviše sedam slave radija. Bluetooth radiji su simetrični tako da svaki od njih može postati master ili slave radio, a konfiguracija piconet je uslovljena trenutkom formiranja. Jedan uređaj može biti master u samo jednoj piconet.

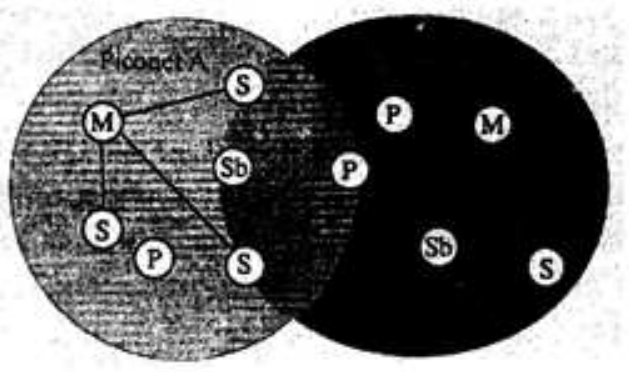

Sl. 5 - Mrežna topologija

\section{Konkurentne tehnologije}

Pored Bluetooth tehnologije postoje i mnoge druge tehnologije kao što su IrDA, Home RF (SWAP), koje obezbeduju slicne ili povezane servise. Iskustvo je pokazalo da je međusobna saradnja medu tehnologijama mnogo bolja od njihove konkurencije. Da bi Bluetooth i druge tehno- 
logije imale perspektivu na tržištu, one moraju koegzistirati i biti interoperabilne.

Bluetooth $u$ odnosu na standard 802.11 - Danas, Bluetooth i 802.11 koriste razlicite radijske proizvode kao sto su dve PC Card. Udaljenost između antena određuje nivo interferencije ili koegzistencije dva proizvoda unutar istog PCija. Bluetooth PC card i 802.11 PC card su utisnute u susedne PC card slotove, pri cemu antenska interferencija neće uticati na zajednicki rad. Iako $802.11 \mathrm{~b}$ i Bluetooth rade na $2,4 \mathrm{GHz}$ ISM opsega, mogućnost delovanja interferencije je mala s obzirom da Bluetooth uredaji koriste frekvencijsko skakanje, a većina WLAN uredaja koristi direktnu sekvencu. Teoretskom studijom, koju je izvrsio Ericsson a odnosi se na uticaj 802.11 mreže na Bluetooth radio, utvrđeno je da je maksimalna degradacija direktne propusne sposobnosti za scenario najgoreg slucaja $22 \%$. Za razliku od 802.11 , Bluetooth danas ne podržava roaming. $\mathrm{Za}$ WLAN se pokazalo da 802.11 tehnologija dobija prednost u komercijalnoj upotrebi. Veća propusna sposobnost, veći domet i druge karakteristike, pokazale su se pogodnijim za WLAN od Bluetooth tehnologije.

Bluetooth $u$ odnosu na infracrvenu tehnologiju - Kao i infracrvena tehnologija, Bluetooth tehnologija je razvijena sa ciljem da bude siroko implementarna tehnologija niske cene. Neki nivoi softvera koje koristi Infracrvena tehnologija, delovi su Bluetooth standarda. Za razliku od infracrvene tehnologije, koja za rad zahteva optičku vidljivost između uredaja, Bluetooth signal delimično može prolaziti kroz tanke prepreke (staklo, gipsani zidovi,...) koristeći radio-tehnologiju kao svoj medijum. IrDA ima veću brzinu prenosa podataka. Za Bluetooth iznosi 1 $\mathrm{Mb} / \mathrm{s}$ dok je za IrDA do $4 \mathrm{Mb} / \mathrm{s}$. IrDA je prikladnija tehnologija za aplikacije kod kojih je značajniji propusni opseg od ogranicenja IrDA-e kao sto je zahtev za linijom posmatranja.

$S$ obzirom na Cinjenicu da IrDA ima znacajnu prednost $\mathrm{u}$ odnosu na Bluetooth u vremenu instaliranja baze, $i$ dalje ce se nastaviti sa integracijom IrDA tehnologije u notez računarima i drugim ručnim uredajima. Instalirana baza za Bluetooth raste, a time ce i potrebe za IrDA tehnologijom opadati, što se ne ocekuje za još nekoliko godina, tako da ce i Bluetooth i IrDA tehnologija medusobno koegzistirati.

S obzirom da komunikacije sa IrDA zahtevaju liniju posmatranja između uređaja, mnogo je teže prisluškivati IrDA vezu nego Bluetooth. Bluetooth SIG je naznacila sigurnost tehnologije ukljucivanjem propisa za autentičnost i enkripciju podataka zasnovanoj na ključ kriptografske tehnologije javan/privatan. Pri proceni sigurnosti svake tehnologije treba poci od procene specificnog korisnickog modela i kolicine informacija koja se prenosi. Polazeći od ovakve procene IrDA može biti prihvatljivija tehnologija za neke aplikacije.

Bluetooth $u$ odnosu na SWAP - Tekući SWAP ima veću instaliranu bazu u odnosu na Bluetooth, ali se ocekuje da ce Bluetooth u tome prevagnuti. Bluetooth je tehnologija za povezivanje uređaja bez kablova. Namera je da se obezbede veze kratkog dometa između mobilnih uređaja i na Internet, preko uređaja za premosccenje sa različitim mrežama (žicanim $i$ bežičnim) koje pružaju Internet mogućnost. Home RF SWAP je bežična tehnologija 
Kratak uporedni pregled tehnologija

\begin{tabular}{|l|l|l|l|l|l|}
\hline & $\begin{array}{l}\text { Vrsna brzina } \\
\text { podataka }\end{array}$ & Domet & Relativna cena & $\begin{array}{l}\text { Mrezna podrska } \\
\text { govoru }\end{array}$ & $\begin{array}{l}\text { Mrezna podrska } \\
\text { podacima }\end{array}$ \\
\hline IEEE 802.11 & $2 \mathrm{Mbps}$ & $50 \mathrm{~m}$ & srednja & preko IP & TCP / IP \\
\hline IrDA & $16 \mathrm{Mbps}$ & $<2 \mathrm{~m}$ & niska & preko IP & preko PPP \\
\hline Bluetooth & $1 \mathrm{Mbps}$ & $<10 \mathrm{~m}$ & srednja & preko IP i cellular & preko PPP \\
\hline Home RF & $1,6 \mathrm{Mbps}$ & $50 \mathrm{~m}$ & srednja & preko IP i PSTN & TCP/IP \\
\hline
\end{tabular}

optimizovana za kućnu sredinu. Njena osnovna upotreba je da obezbedi data networking i dial tones između uredaja kao što su PC-ijevi, cordless (bežični) telefoni, Web Tablets i broadband cable ili DSL modem. Obe tehnologije dele isti frekvencijski spektar pri cemu ne dolazi do interferencije kada rade $u$ istom prostoru.

Kratko poredenje izmedu tehnologija prikazano je u tabeli.

\section{Sigurnost}

Bluetooth standardom predviđa se do 128-bitna sigurnost da bi se obezbedio prijem u zajednickoj sredini. Standard, takođe, ukljucuje logo sertifikacioni program da bi se obezbedila kompatibilnost među svim razlicitim uređajima koji sadrže Bluetooth.

Bluetooth koristi 4 bazna ključa u sigurnosnom mehanizmu, $i$ to su: 48-bitna fiksna javna adresa koja je jedinstvena za svaki uređaj, 128-bitni pseudoslucajni broj koji se generiše pri svakoj transakciji i dva tajna ključa. Jedan tajni ključ je 128-bitni privatni korisnički ključ za autentičnost, a drugi je privatni korisnicki enkripcioni ključ koji može varirati od 8 bita do 128 bita. Enkripcioni ključ može varirati u svojoj dužini da bi se obezbedio eksport restrikcija. Pored ovih osnovnih ključeva, drugi ključevi se ge- nerišu za svaki link, kako bi se osiguralo da drugi Bluetooth uređaji koji ne cine piconet ne mogu nehoticno ili hotimicno prisluskkivati Bluetooth vezu.

Bluetooth standard predviđa tri nivoa ili režima sigurnosti, $\mathrm{i}$ to su:

- Non-Secure - uredaj ne inicira ni jednu sigurnosnu proceduru. $U$ ovom reŽimu svakome je dopušteno da priđe uređaju i da koristi njegove servise. Ovaj režim je predviđen da se koristi za rad kod javnih uredaja, kao sto je to stampac;

- Service Level Enforced Security $\mathrm{U}$ ovom režimu dozvola za pristup uredaju zavisi od zahteva servisa. Na primer, dozvoljena je mogućnost prebacivanja fajlova u PC ali ne i pristup kalendaru ili telefonskom imeniku uređaja;

- Link Level Enforced Security Ovo je režim najveće sigurnosti. On zahteva autentifikaciju i autorizaciju pre dobijanja dozvole za pristup bilo kom servisu koji obezbeđuje uređaj. Ovaj režim je predviđen za celijske telefone koji se jedino mogu koristiti individualno ili od strane ograniŁenog broja pojedinaca.

\section{Standardizacija Bluetooth tehnologije}

Za razliku od mnogih drugih bežicnih standarda, Bluetooth bežični standard ukljucuje i definicije za linijske i aplikaci- 
one nivoe, za proizvodače koji razvijaju proizvode i koji podržavaju data, voice $\mathrm{i}$ content - centric aplikacije. Bluetooth standard sadrži informacije koje su neophodne da razlixiti uredaji koji podržavaju Bluetooth bežičnu tehnologiju mogu komunicirati jedan sa drugim sirom sveta. Dokument standarda podeljen je u dve sekcije: Core Specification i Profile Definitions. Core deo specificira komponente kao što su radio, osnovni opseg, link manager, service discovery protokol, prenosni nivo i interoperabilnost sa razlicitim komunikacionim protokolima. Profile deo specificira protokole i procedure potrebne za razlixite tipove Bluetooth aplikacija.

Bluetooth SIG (Special Interest Group) je industrijska grupa koju cine vodeći proizvođaci telekomunikacione i kompjuterske opreme, kao sto su 3COM, Ericsson, Lucent, IBM, Intel, Microsoft, Nokia, Toshiba, i dr. Oni su pokretači razvoja ove tehnologije i njenog plasiranja na tržištu.

Postoji više verzija Bluetooth standarda, kao što su 1.0, 1.0A objavljeni juna 1999. godine, 1.1 objavljen krajem 2000. godine.

Tekući Bluetooth standard (verzija $1.0 \mathrm{~b})$ podržava sledeće profile:

- General Access - procedure koje se odnose na istraživanje / link menadžment \& sigurnosne nivoe;

- Service Discovery - istraživanja servisa dostupnih u drugim Bluetooth uredajima;

- Cordless Telephony - mogućnost da celijski telefon radi kao bežični telefon kada se nalazi u blizini bazne stanice;

- Intercom - definiše intercom funkciju u celijskim / mobilnim telefonima koristeći Bluetooth kao radio-link;
- Serial Port - simulacija serijskih ulaza za aplikacije koje tradicionalno koriste žičani serial port $\mathrm{i}$ interfejs;

- Headset - definiše predaju / prijem govora i podataka preko Bluetooth linka;

- Dial-up Networking - primarno definisan kao link između celijskog telefona i kompjutera. Profil je definisan tako da kompjuter može inicirati data coll $\mathrm{i}$ primiti data coll u zavisnosti od postavke korisnika;

- Fax - ćelijski telefon ili modem mogu se koristiti kao faks interfejs za kompjuter za slanje i prijem faksova;

- LAN Access - uspostavljanje personalne mreže korišćenjem Point-to-Point Protocol-a (PPP);

- Generic Object Exchange (OBEX) - definiše procedure koje se koriste za transfer fajlova, object push i sinhronizacione profile;

- Object push - mogućnost da se postavi i izvuce poslovna kartica ili izvr§i ugovaranje sastanaka;

- File Transfer - browse file system on, kreiranje ili brisanje fajlova sa aktivnim folderima, ili transfer fajlova od / ka drugom Bluetooth uređaju;

- Synhronization - razmena personalnih informacija, kao što su kalendar i telefonski imenik. Takođe, korišćenjem mobilnog telefona ili kompjutera, kada su u opsegu pokrivanja, automatski se startuje sinhronizacija.

Dok je standard 1.0 primarno fokusiran na scenarije zamene kablova, Bluetooth 2.0 standardom se teži da se pokrije mnogo vise naprednih i korisnih korisnickih modela. Za podrsku razvoju 2.0 standarda, Bluetooth SIG je formirala nove radne grupe da istraže niz novih ko- 
risničkih modela iz čga ce proizići formiranje novih profila 2,0 standarda. Bluetooth $2.0 \mathrm{SIG}$ radne grupe ukljucuju:

- radio - istraživanja sa povećanim brzinama prenosa (do $2 \mathrm{Mbps}+$ ), poboljSana koegzistencija sa drugim $2,4 \mathrm{GHz}$ radijima (posebna radna grupa) $\mathrm{i}$ poboljŁanja funkcija osnovnog opsega;

- Personal Area Networking (PAN) - koncentracija je na opšte IP umrežavanje (uključujući sigurnost) u prostoru adhoc povezivanja;

- Human Interface Device (HID) postojeća industrijska specifikacija za kompjuterske periferije, kao sto su tastature, miševi, džojstici i dr., Bluetooth HID radna grupa razviće profil za korisccenje HID preko Bluetooth;

- Audio/Video - radna grupa za aplikacije istražuje visoke $\mathrm{i}$ multimedijalne mogućnosti koje bi se realizovale pomoću Bluetooth-a, kao što su movie/video čipovi, muzika preko bežičnih slušalica i video konferencija;

- Printer Profile - udružen sa bezgajtanskim kompjuterskim korisnickim modelom, Printing Work Group ce raditi direct-to-printer scenarije korisćenjem peer-to-peer Bluetooth povezivanja (fokusirano na Universal Plug and Play i Solutation tehnologije);

- Enhanced Service Discover Protocols - proširenje 1.0 standarda kojim se teži da se formalizuje Service Discovery Protocol sa profilima za mapiranje izabranih Service Discovery protokola za Bluetooth;

- Local Positioning - implementiranje Bluetooth-a kao sistema za odredivanje blizine „lokalnih" geografskih pro- stora i davanje informacija o poziciji drugim aplikacijama;

- Still Image - komponenta Instant Post Card Usage Model, osnovni princip je bežičan prenos foto slika sa digitalne kamere na mnoge druge uredaje koji imaju Bluetooth.

\section{Zaključak}

Za razliku od WLAN mreža, koje su projektovane da efikasno povežu velike grupe ljudi preko zajedničke magistrale sistema, Bluetooth tehnologija je projektovana da poveže mobilne uređaje preko personalnih privatnih veza, odnosno da zameni kablove koje nose mnogi mobilni korisnici.

Bluetooth tehnologija pokusava da konkuriše mogućnostima koje pružaju kablovi u domenima cene, sigurnosti i drugih mogućnosti koje se pružaju mobilnim korisnicima. S obzirom da je to tehnologija u razvoju, ona treba da bude sigurna isto kao i kablovi (da podržava application/link-layer autorizacije, autentičnosti i enkripcije); da bude proizvođena po gotovo istoj ceni kao i kablovi (projektovana kao jedan CMOS radiocip, obezbeđujući na duži period cenu od 5 USD i end-point radio); da može da se poveže sa raznim uređajima koji su dostupni mobilnom korisniku (sedam simultanih veza) i podrži brzine prenosa podataka koje su saglasne sa potrebama mobilnih korisnika (1 Mega symbol per second po piconet); da podrži mnoge simultane i privatne mreže (stotine privatnih piconet koje su unutar dometa jedna druge); da podrži tipove podataka koje koriste mobilni korisnici (govor i poda- 
tak); i da bude vrlo male potrošnje snage i kompaktna da bi podržala male portabl uredaje u koje ce tehnologija biti integrisana. Na kraju, tehnologija treba da bude globalna tako da korisnici mobilnih uređaja $u$ toku putovanja mogu raditi sa uređajima na koje nailaze u drugim delovima sveta.

Bluetooth je tehnologija u ekspanziji. Postoje planovi za dodavanje mnogo novih aplikacionih profila i sa jakom SIG iza Bluetooth-a standardizacija aplikacionih profila bice u budućnosti sasvim obezbeđena.

\section{Literahura:}

[1] www.wirelless netvorking technology, novembar 2002.

2 www.bluetooth technology, novembar 2002.

3] www,bluetooth com., novembar 2002.

14] Rejman E: Bluetooth Puts Bite On Mobile Communications, Microwave journal, july 2000. 